\title{
Maria Gravari-Barbas, Aménager la ville par la culture et le tourisme
}

coll. "Ville-aménagement", éditions Le Moniteur, 2013

\section{Philippe Duhamel}

\section{OpenEdition}

\section{Journals}

Édition électronique

URL : http://journals.openedition.org/tourisme/393

DOI : 10.4000/tourisme.393

ISSN : 2492-7503

Éditeur

Éditions touristiques européennes

\section{Édition imprimée}

Date de publication : 1 décembre 2014

Pagination : 105-106

ISSN : 2109-5671

\section{Référence électronique}

Philippe Duhamel, « Maria Gravari-Barbas, Aménager la ville par la culture et le tourisme ». Mondes du Tourisme [En ligne], 10 | 2014, mis en ligne le 30 septembre 2015, consulté le 22 septembre 2020. URL : http://journals.openedition.org/tourisme/393 ; DOI : https://doi.org/10.4000/tourisme.393

Ce document a été généré automatiquement le 22 septembre 2020.

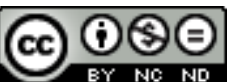

Mondes du tourisme est mis à disposition selon les termes de la licence Creative Commons Attribution - Pas d'Utilisation Commerciale - Pas de Modification 4.0 International. 


\title{
Maria Gravari-Barbas, Aménager la ville par la culture et le tourisme
}

coll. “Ville-aménagement”, éditions Le Moniteur, 2013

\author{
Philippe Duhamel
}

\section{RÉFÉRENCE}

Maria Gravari-Barbas, Aménager la ville par la culture et le tourisme, coll. "Ville-

aménagement", éditions Le Moniteur, 2013.

1 Aménager la ville par la culture et le tourisme rend compte des travaux du Club villeaménagement menés en 2010, réflexions pilotées par Hervé Dupont, Bertrand Ousset et Jean-William Souffront, spécialistes de l'urbanisme et de l'aménagement. La signataire de l'ouvrage, Maria Gravari-Barbas, architecte et professeur de géographie à l'université Paris I Panthéon-Sorbonne, “a accompagné [ce groupe] de A à Z" ; elle en synthétise les échanges autour d'une problématique centrale d'une grande actualité : quand la culture et le tourisme deviennent un mode opératoire d'aménagement urbain, suscitant des projets d'équipement qui alimentent la concurrence, pour ne pas dire la compétition, entre les villes. Il s'agit aussi de montrer combien la culture et le tourisme sont devenus, pour les villes, des enjeux cruciaux pour "tenir", "renforcer" leur rang dans la mondialisation (à l'instar des technologies ou de l'industrie) et pour créer du lien dans des villes très étendues, très "distendues".

Quatre chapitres structurent cet ouvrage. Le premier, "Compétition territoriale", évoque l'affirmation progressive de la question de la culture et du tourisme dans la construction contemporaine des villes. Le deuxième, "Culture et tourisme, vecteurs de projets urbains", entreprend de croiser projet urbain, d'une part, et projet culturel ou touristique, d'autre part, et de voir comment l'un et l'autre s'articulent. Il pousse la réflexion jusqu'aux exemples "extrêmes" où le projet urbain est un projet culturel ou touristique. Le troisième chapitre, "La reconquête de l'espace urbain par le tourisme et 
la culture", se saisit d'autres aspects de la question : comment la culture et le tourisme s'emparent de lieux urbains préexistants et les "détournent" de leur affectation première (industrielle, par exemple), soit par le processus de requalification, soit par leur diversification (La Défense) ; comment l'événement donne sens autrement à la ville et comment les rythmes urbains s'en trouvent modifiés. Le dernier chapitre, "Nouvelles synergies d'acteurs", plante les enjeux autour des relations entre touristes et habitants, entre aménageurs et opérateurs touristiques et culturels, enjeux qui peuvent parfois provoquer des tensions fortes, car habiter la ville ne signifie pas la même chose lorsque notre quartier est investi par une dimension touristique ou culturelle nouvelle ou amplifiée ; car construire la ville relève d'autres postures lorsque la logique productive, au sens classique du terme, n'est plus le fer de lance des aménagements et des équipements.

Le contenu de cet ouvrage montre immédiatement sa pertinence en ces temps de "tournant recréatif" de la société, expression proposée par Mathis Stock (2007). Celle-ci exprime un moment particulier où la "société monde", après un stade industriel de développement, identifie de nouveaux moteurs qui conduisent à dynamiser les territoires par le tourisme, les loisirs (shopping, événements) et la culture. Ce triptyque est devenu clairement la panacée, car tous les territoires, quelles que soient leur histoire ou leur actualité, peuvent prétendre à transformer leur destinée. Cela rappelle le vieil adage : "Il n'y pas de territoires sans avenir mais seulement des territoires sans projets." Jean Frébault, président du Conseil de développement du Grand Lyon, conclut d'ailleurs l'ouvrage en indiquant que "la culture concerne tous les territoires, pas seulement les métropoles". Le meilleur exemple de cette dynamique nouvelle est l'émergence à la fin des années 1990 de villes conçues autour de cette combinaison originale et nouvelle. Les Émirats arabes unis en sont l'icône "parfaite" et la référence incontournable.

4 Pour autant, aménager la ville par la culture et le tourisme ne va pas de soi. L'ouvrage montre bien, à travers les multiples exemples pris dans les pays occidentaux (exclusivement - ce que l'on pourra regretter), les difficultés d'une telle entreprise. Ainsi la réalisation de grands équipements culturels liés ou non à la "starchitecture" que toutes les villes souhaitent, conduit à une prise de risque très grande, voire insurmontable parfois quand le public n'est pas totalement au rendez-vous. Le même constat prévaut pour les événements.

5 Toutefois ces derniers n'engagent pas les villes ou les territoires de la même manière car, inscrits dans des temporalités courtes, ils ne sont pas pérennisés si le succès n'est pas suffisant. Ils ont néanmoins un rôle crucial dans la visibilité, la renommée et le rayonnement des villes aujourd'hui ; ils constituent par ailleurs un moment possible de cohésion sociale permettant le rassemblement de toutes les populations locales, régionales, nationales et internationales. Cette "événementialisation" des temps urbains montre aussi l'investissement de temporalités nouvelles comme la nuit qui, là encore, assure des marges de développement et des conquêtes spatiales et temporelles inattendues.

6 Bref, on l'aura compris, Aménager la ville par la culture et le tourisme est un livre très utile et très intéressant. Il permet de connaître et de comprendre la situation contemporaine et les enjeux, pour la société comme pour les professions concernées, que révèlent la conception et la réalisation de ces projets. Cet ouvrage a un objectif très clair : exposer, décrire et soulever les problèmes et les ambiguïtés sans les analyser. On espère alors que l'auteur saura tirer profit de tout cela pour nous proposer prochainement un 
nouvel ouvrage, plus scientifique, c'est-à-dire plus critique et plus approfondi sur les tensions, les difficultés et les échecs de ces logiques d'aménagement, un ouvrage qui donnera aussi la parole aux habitants et aux touristes afin qu'elle soit croisée avec l'approche des professionnels, très prégnante ici.

\section{NOTES}

1. Mathis Stock, “European Cities: Towards a Recreational Turn?", Hagar. Studies in Culture, Polity, and Identities, vol. 7, $\mathrm{n}^{\circ}$ 1, 2007.

\section{AUTEURS}

PHILIPPE DUHAMEL

Université d'Angers [philippe.duhamel@univ-angers.fr 